\title{
Circular economy in built environment and real estate industry
}

\author{
Janis Zvirgzdins ${ }^{1}$, Kaspars Plotka ${ }^{2}$, Sanda Geipele ${ }^{3}$ \\ Institute of the Civil Engineering and Real Estate Economics, Riga Technical University, Riga, Latvia \\ E-mail: 'Janis.Zvirgzdins_1@rtu.lv (corresponding author)
}

\begin{abstract}
The concept of circular economy have gained a popularity in the scientific areas for the past decades due to raising influence of climate change, overpopulation, deforestation, resource depletion, urbanization, pollution and other global issues. Real estate is crucial aspect for every human being, because majority of people spend majority of their lifetime in buildings which are mainly located in cities. Purpose of the study is to reflect how built environment and real estate industry can benefit from the features of circular economy concept while promoting the practices of sustainable development. Authors have carried out a study based on the methodology of literature review and state of the art review to show how features of circular economy can support practices of sustainable construction. Results show that the construction processes can be supported by features of circular economy throughout the whole life cycle of construction project including logistics, supply chains, design, manufacturing process, exploitation and maintenance of real estate and reusing the building materials. Research indicates that urban circular economy contributes to the development of sustainable societies. Additionally, efficient implementation of circular construction requires profitability for majority of stakeholders.
\end{abstract}

Keywords: built environment, circular construction, circular economy, real estate, sustainable development.

\section{Introduction}

New building tendencies have shown real estate objects that are almost energy neutral or even generate and store energy. From 2020 new European Union standards will require new buildings to be at least energy neutral when in use. Additionally, society is becoming more aware of environmental issues and therefore, customers are more often demanding further reductions in the environmental impact of buildings and increased real estate performance. These requirements can be achieved by making the construction process and the manufacture of building materials more sustainable. And in order to do that the basis of further development of real estate and built environment should be circular construction with focus on the reuse of building materials (van Sante, 2017).

A rapid development of studies related to environmental issues is witnessed in recent years due to the substantial environmental burdens associated with the building industry. Main impacts are linked to energy consumption patterns and carbon dioxide emissions. Buildings produce $\mathrm{CO}_{2}$ emissions in two ways: 1) during their exploitation through heating etc. (approximately $35 \%$ of the total $\mathrm{EU} \mathrm{CO}_{2}$ emissions); 2) during the construction and manufacture of the building materials (approximately $5 \%$ of the total $\mathrm{EU} \mathrm{CO}_{2}$ emissions).

Global studies have shown that investments of only two percent of the global gross domestic product (GDP) in the development of ten major sectors, including civil engineering, agriculture, energy, forestry, fisheries, industrial production, transport, tourism, waste management and water resources, can serve as an incentive to transition to a resource-saving and low carbon economy. Recent research of Tupenaite et al. indicates that energy and atmosphere considerations, materials and waste management are among the top priorities of the new residential projects in the Baltic States (Tupenaite, Lill, Geipele, \& Naimaviciene, 2017). Therefore, developers are encouraged to build new energy efficient residential buildings from environmentally friendly, reused and recycled materials, which are the fundamentals of the concept of circular construction.

\section{Circular economy and sustainability}

The concept of the circular economy contrasts with the traditional 'linear economy' which turns raw materials into waste in the production process and which is seen to lead to ecological pollution and to the removal of natural capital. In theory, the concept of the circular economy embraces all stages of the product life cycle from product design and production process, followed by marketing and consumption to waste management, recycling and re-use. Within 
circular economy an initial focus is on designing products that are more resource efficient throughout their life cycles. Goal is to make products more durable, easier to repair and to recover as well as identify potentially useful materials from the products when their initial lifespan is over. The circular economy also demands greater efficiency in production processes. The focus is on reducing the environmental and social impact of production, for example, through more sustainable sourcing and promotion of innovative industrial processes (Jones \& Comfort, 2017).

Figure 1 illustrates seven pillars of circular economy. It can be stated that concept is highly linked with sustainability and sustainable development. It is aimed at providing health and wellbeing of humans and other species, supporting biodiversity, generating value in measures beyond financial, extracting water in a sustainable rate which means that the speed of consuming water should not be higher than the speed of natural hydrological cycle. Materials within the concept of circular economy are cycled at continuous high value and all the energy is based on renewable energy sources. Additionally, human society and culture are being preserved.

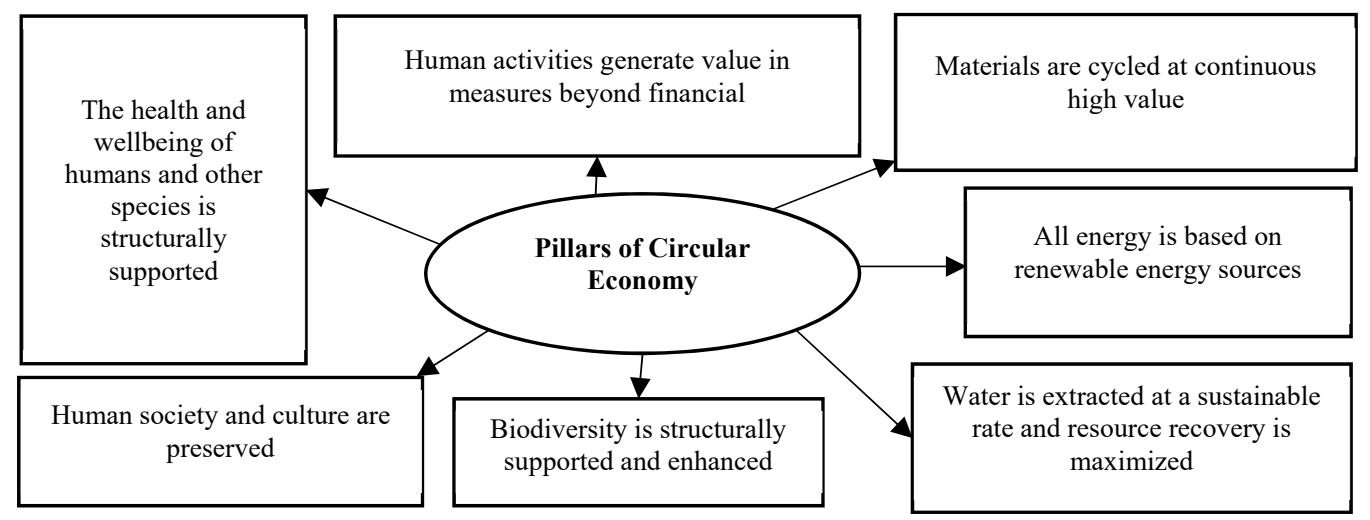

Figure 1. Pillars of circular economy (source: Kubbinga et al., 2018)

The conceptualization of circular economy has evolved through the years and it has been gaining momentum since the late 1970s (Geissdoerfer, Savaget, Bocken, \& Hultink, 2017). Principles of circular economy rely on better management of resources and waste by minimizing (or closing) material and energy loops (Geissdoerfer et al., 2017; Lacy \& Rutqvist, 2015; Pomponi \& Moncaster, 2017). Pomponi and Moncaster according to their research results in 2017 stated that green supply chains and waste reduction have been the main drivers of research due to the evident opportunities, such as reductions in energy use, environmental impacts and waste production. Strategies for engaging a circular economy in the built environment are long-lasting design, maintenance, repair, reuse, remanufacturing, refurbishing and recycling. Therefore, construction as an industry should be implementing designs and systems with improved long-term life cycle performance. The key aim is to consider closed loop design principles. These principles can be defined as a construction involving materials and building elements from old buildings that can be endlessly recycled or reused through natural or industrial processes (Sassi, 2008).

In 2008, Sassi defined criteria by which building materials can be assessed in terms of forming part of a closed loop (Sassi, 2008). In 2014 Jaillon and Poon demonstrated that the promotion of a closed-loop material cycle is critical to contribute to sustainability minimizing carbon dioxide emissions and natural resource consumption (Jaillon \& Poon, 2014). Meanwhile in 2014 Silvestre et al. proved that assessment of waste flows is an important source of data for decision-making at the end-of-life of building materials (Silvestre, de Brito, \& Pinheiro, 2014). In 2007 Schultmann and Sunke researched energy savings that could be afforded through using different recovery techniques on deconstruction projects (Schultmann \& Sunke, 2007). Previously mentioned studies support the idea that there are areas of opportunity to maximize the benefits of the resources on the end-of-life stage of buildings. In an analogous manner, the increase of benefit potential can be recognized throughout the building life cycle which is based on identification of reusable building materials which can promote the transition towards a circular economy (Sanchez \& Haas, 2018).

\section{Sustainable construction}

Sustainability in construction considers the potential interaction with environment to provide services with synergistic effects. Key sustainability objectives are respect to materials selection, closing material loops and eliminating solid, liquid and gaseous emissions. Closed loop describes a process of keeping materials in productive use by reuse and recycling rather than disposing them as waste at the end of building or product life cycle. Products in closed loops can be easily disassembled, and the material ingredients are able to be recycled. According to fact that recycling process is not entirely efficient, the dispersal of residues in the biosphere is inevitable. Therefore, recycled materials must be ecologically harmless. Most common construction materials are not completely recyclable. They rather are downcyclable for lower value reuse, for example as a filling material. Fortunately, concrete, fill dirt, bricks, mortar, tiles and similar low-tech materials are made with low ecological toxicity. 
Sustainability linked to building industry and real estate has shifted from an original focus on cleaner and leaner delivery of conventional projects to a restorative and regenerative approach. Sustainable built environment has been mainly focused on the development of new high-performance green buildings and retrofitting, rather than research in life cycle performance in terms of sustainability (Sanchez \& Haas, 2018; Ofori, 1998; Kibert, 2007; Du Plessis, 2007; De Wolf, Pomponi, \& Moncaster, 2017). Therefore, authors suggest considering circular as more comprehensive approach when considering sustainability in context of construction.

In 2017 Pomponi and Moncaster developed six dimensions for building research in a circular economy: environmental, technological, economic, societal, governmental and behavioural (Pomponi \& Moncaster, 2017). Environmental dimension is aimed at lowering the negative environmental impacts and preferring reuse and renovation over developing new construction objects. Ultimate goals of environmental dimension are resource conservation and biodiversity preservation. Economic dimension stands for creating business and construction models in order to provide opportunities for stakeholders to achieve profitability. Societal dimension stands for creating a co-responsible society. It emphasizes that education has an important role in creating the one. In circular construction social dimension can be reflected as learning to design and build with reused and reclaimed materials. 'People' dimension can also be linked to 'sharing economy', which is aimed at using real estate object as a service, not necessarily owning it. Technological dimension is considered as main aspect to enable and maintain circular loops. It is connecting demand and supply, handling, storing and managing huge amount of data that is required by circular economy and sustainable built environment. Well executed technology strategy according to reusability principles can create synergy effect between dimensions and lead to the ultimate goal of sustainable value creation in the economy, society and environment. Governmental dimension can be described as a need for planning authorities to be aware of their local circular economy context which is in accordance with environmentalist slogan: 'think global, act local'. It is essential to make sure that governmental subjects and members of decision making groups understand the diversity and individual nature of the challenges ahead. In the view of authors behavioural dimension includes key role to achieve comprehensive circularity. It refers to the assumption that it is people rather than technologies, who are the key to lead the transition to circular economy. From the view of circular construction stakeholders have the key role for bringing concept to practice.

Figure 2, which is developed by Pomponi and Moncaster (2017) reflects the dimensions which are covered by concepts of green buildings, sustainable buildings and circular buildings. While green building conception considers environmental and technological research dimensions, concept of sustainable buildings adds the missing parts of sustainable development (people, profit, planet) concept considering economic and societal dimension as well. However, the most holistic approach is offered by circular building (circular construction) conception which also takes into account governmental and behavioural research dimensions.

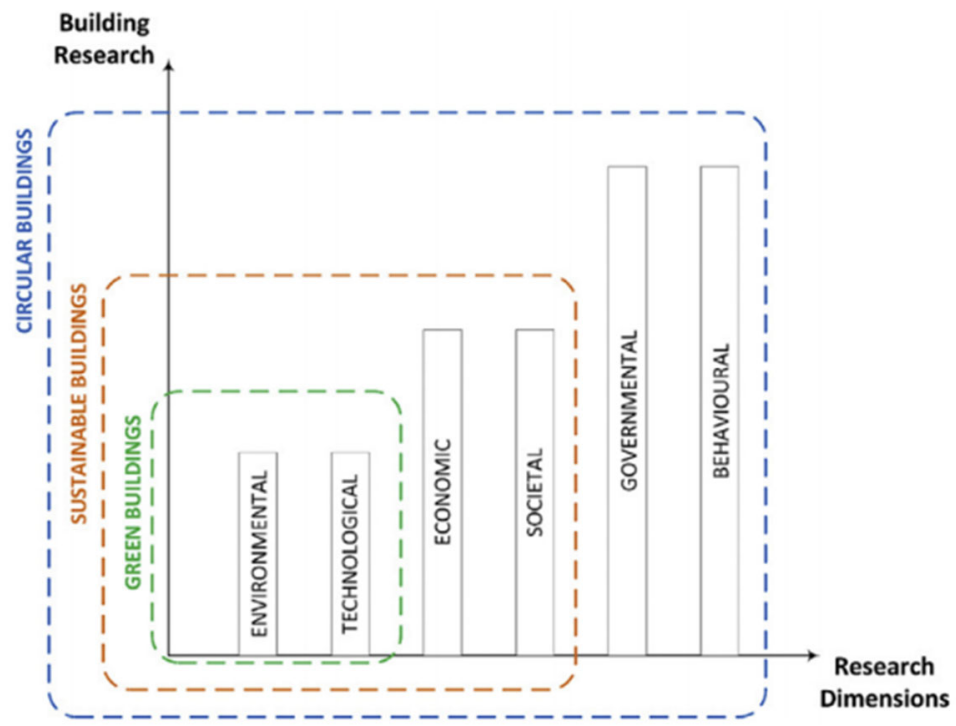

Figure 2. Research dimensions of building research (source: Pomponi \& Moncaster, 2017)

\section{Circular economy in construction and real estate}

There are several ways of how construction industry is approaching the concept of circular economy in Europe. Paying attention to real estate sector it is obvious that advanced circular processes already exist. The owner makes the building available to a series of tenants while making minimum amount of modifications. There are few products that last as long as real estate. Monumental buildings have been in use for centuries. Only few other goods have such a long life span (van Sante, 2017). 
Circular construction has the objective to recover as much of the economic, social and ecological value of a building as possible during the process of adaptive reuse. The potential benefits of adaptive reuse rely on the fact that it is possible to take away components from an obsolete building and then recycle, repair, reuse or remanufacture them. Real estate recovery methods include design for disassembly, design for maintainability, design for reuse, design for remanufacturing and design for recyclability (Smith \& Hung, 2015).

Pukite and Geipele indicate that effective building maintenance, which is essential to circular construction practices, includes preserving reputation and value of investments, maintaining the building in a condition, which allows it to accomplish its purpose and present a good outer shell (Pukite \& Geipele, 2017).

Developing a circular economy requires multiplex activities at local, regional, national and global scales. In order to change and lead to more sustainable way of living, all stakeholders have to implement six main actions related to circular economy: regenerate, share, optimize, loop, virtualize, exchange.

Regenerating stands for shifting to renewable energy sources, regenerating the health of ecosystems and returning the recovered biological resources to biosphere. Sharing stands for maximizing utilization of products through peerto-peer sharing of privately owned products or public sharing of product pools; reusing them throughout their technical life spans and extending these life spans by maintenance, repair and design for durability. Examples can include sharing cars and homes. The authors of this article note that this situation can be described as a synergistic 'win-win' situation, because house owners make their empty houses profitable and customers save significant amount of money picking shared type of housing instead of a hotel room. Optimizing in context of circular economy stands for improving the performance and efficiency of products, removing waste from supply chains and using big data and automation. Additionally, none of optimizing actions requires change of product or technology. Looping refers to keeping components and materials, both finite and renewable, in closed loops. Virtualizing means delivering utility virtually books, music, online shopping, virtual offices, etc. Exchanging stands for replacing old materials with advanced renewable ones, applying new technologies, for example, electric engines and 4-D printing.

Mckinsey Center for Business and Environment in 2016 carried out a research evaluating the profit potential of different economic activities according to the previously mentioned six main actions of circular economy. According to the research results, construction has high profit potential in sharing and looping activity categories and medium profit potential in optimizing, virtualizing and exchanging activity categories. Additionally, real estate activities have shown high profit potential in sharing activities. Optimizing and looping activity categories have medium profit potential regarding real estate activities. Based on this study, authors acknowledge that construction and real estate activities have a potential not only to provide society with environmental and social, but also economic benefits (Bouton et al., 2016).

In order to promote circular processes in the construction and real estate sector, links between all phases in the value chain are necessary to support communication and information transfer across the value network.

The UK Green Building Council point out that economy as whole can benefit from adapting circular economy concept. It is noted that transition to circular economy would mean relevant actions from the stakeholders related to built environment. Real estate developers could be: 1) developing resource efficient products that are easy to repair and disassemble; 2) using delivery and return logistics to recover materials; 3) responsibly sourcing raw materials; 4) designing to minimise waste in product refurbishment and maximise re-use potential; 5) moving to alternative business models, for example, product service systems. Stakeholders linked to design and construction could be: 1) designing out waste; 2) designing for resource efficiency; 3) designing for deconstruction and disassembly; 4) using more renewable energy; 5) reducing carbon footprint over a whole building lifecycle (UK Green Building Council, 2017).

In order to achieve circular construction in practice, the involvement of entire supply chain is needed. For example, architects and owners need to decide whether to reuse or demolish an old building. Construction suppliers should be offering bio-based building materials. Smart demolition allows demolishers to offer high quality used building materials for reuse. Wholesalers could be taking up the role of resources banks, selling used materials (van Sante, 2017).

As we can see in Figure 3, circular construction is linked to aspects of flexibility, health, real estate as raw materials stock and benefits for society. Circular construction should be based on flexible infrastructure and real estate built with non-toxic, ecological, recyclable materials. Real estate objects should have an option to be easily repurposed. They can be considered as raw material stock. Energy from renewable energy sources should be considered as the main energy source whether it is integrated in real estate object or produced nearby. Overall transition to circular construction practices can provide society with benefits, such as cleaner air, urban agriculture opportunities and good public image.

Construction activities create a living environment for a significant part of future generations. Circular construction must ensure that negative impacts on ecosystems are minimized. The impacts of negative built environment practices can contribute to increased air, water and soil pollution. They can have a destabilizing effect on the most significant levels of ecosystems, which can result in a reduction of biomass and influence the food chain, thus contributing to the loss of biodiversity. 


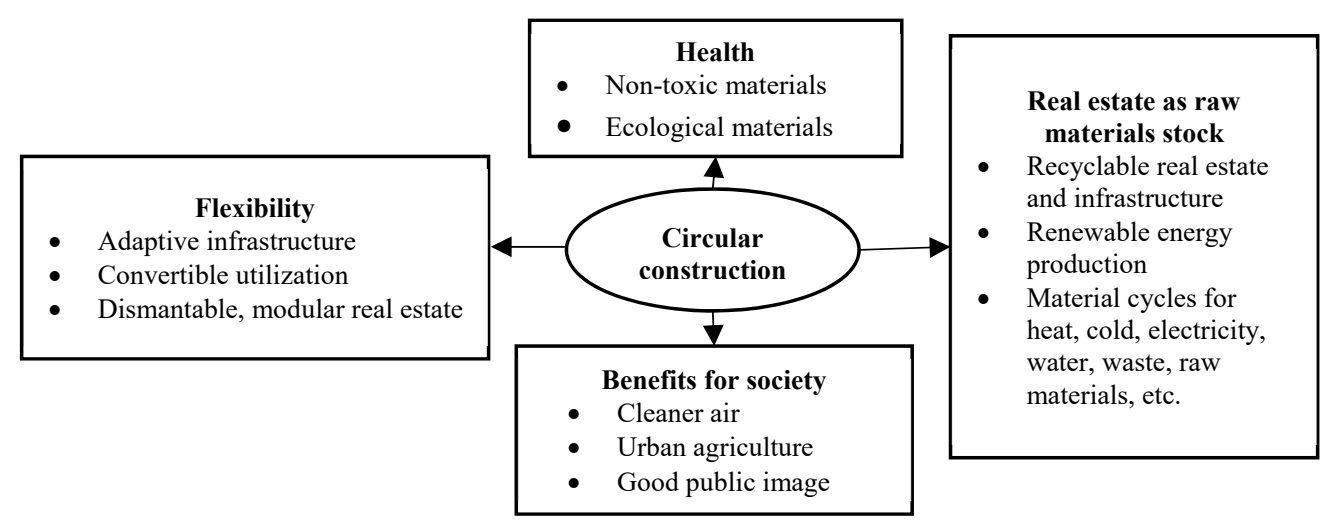

Figure 3. Advantages of circular construction implementation (developed by authors)

Table 1 covers processes and activities of circular construction implementation. For a more comprehensive view, it is divided into 7 categories: materials, energy, water, biodiversity and ecosystems, human culture and society, health and wellbeing, value. The table can be used as a framework for architects and developers on how to design and construct real estate objects according to concept of circular construction. It should be noted that knowledge development and sharing applies for all the categories. Therefore, effective collaboration among all stakeholders is a precondition to successfully implement circular construction practices.

Table 1. Processes and activities of circular construction implementation (adapted from (Kubbinga et al., 2018))

\begin{tabular}{|c|c|c|c|c|c|c|}
\hline Materials & Energy & Water & $\begin{array}{l}\text { Biodiversity } \\
\text { and Ecosystems }\end{array}$ & $\begin{array}{l}\text { Human culture } \\
\text { and society }\end{array}$ & $\begin{array}{l}\text { Health and } \\
\text { Wellbeing }\end{array}$ & Value \\
\hline $\begin{array}{l}\text { Optimal } \\
\text { material use }\end{array}$ & $\begin{array}{l}\text { Minimise } \\
\text { energy } \\
\text { consumption }\end{array}$ & $\begin{array}{l}\text { Minimise } \\
\text { water } \\
\text { consumption }\end{array}$ & $\begin{array}{l}\text { Avoid the loss } \\
\text { of biodiversity }\end{array}$ & $\begin{array}{l}\text { Avoid the loss of } \\
\text { unique cultures } \\
\text { and social } \\
\text { diversity }\end{array}$ & $\begin{array}{l}\text { Avoid toxic } \\
\text { materials and } \\
\text { pollution }\end{array}$ & $\begin{array}{l}\text { Ensure long- } \\
\text { term } \\
\text { aesthetics }\end{array}$ \\
\hline $\begin{array}{l}\text { Reutilisation } \\
\text { of products }\end{array}$ & $\begin{array}{l}\text { Optimise } \\
\text { energy } \\
\text { demand }\end{array}$ & $\begin{array}{l}\text { Water } \\
\text { cascading }\end{array}$ & $\begin{array}{l}\text { Integration of } \\
\text { ecosystem } \\
\text { services }\end{array}$ & $\begin{array}{l}\text { Facilitate shared } \\
\text { amenities and } \\
\text { services }\end{array}$ & $\begin{array}{l}\text { Ensure sufficient } \\
\text { quality of life by } \\
\text { providing an optimal } \\
\text { indoor environment }\end{array}$ & $\begin{array}{l}\text { Knowledge } \\
\text { development } \\
\text { and sharing }\end{array}$ \\
\hline $\begin{array}{l}\text { Circular } \\
\text { materials }\end{array}$ & $\begin{array}{l}\text { Sustainable } \\
\text { and local } \\
\text { energy }\end{array}$ & $\begin{array}{l}\text { Knowledge } \\
\text { development } \\
\text { and sharing }\end{array}$ & $\begin{array}{l}\text { Stimulate local } \\
\text { biodiversity }\end{array}$ & $\begin{array}{l}\text { Knowledge } \\
\text { development and } \\
\text { sharing }\end{array}$ & $\begin{array}{l}\text { Knowledge } \\
\text { development and } \\
\text { sharing }\end{array}$ & \\
\hline $\begin{array}{l}\text { Knowledge } \\
\text { development } \\
\text { and sharing }\end{array}$ & $\begin{array}{l}\text { Knowledge } \\
\text { development } \\
\text { and sharing }\end{array}$ & & $\begin{array}{l}\text { Knowledge } \\
\text { development } \\
\text { and sharing }\end{array}$ & & & \\
\hline
\end{tabular}

\section{Circular construction in cities}

At present more than one-half of the global population lives in cities and it is forecasted that by $205070 \%$ margin will be reached. The quality and resource rationality of cities will become an increasingly critical issue. Cities are engines of economic growth, generating approximately $85 \%$ of global Gross domestic product (GDP). They are places where people live, work, innovate, meet and consume considerable amounts of resources (World Economic Forum, 2018). Cities today occupy approximately $2 \%$ of the total land surface in the world. They consume over $60 \%$ of our energy, $75 \%$ of natural resources, generate approximately $70 \%$ of waste and claim responsibility for $70 \%$ of greenhouse gas emissions (Barrie, 2017). Therefore, cities have an essential role in the transition to a circular economy; especially mentioning that greatest amount of construction and real estate activities is demanded by development of urban environment.

Within the wider context of water, energy, transport and infrastructure, the built environment - including real estate development and urban facilities - is responsible for a large percentage of greenhouse gas emissions, consumption, and waste (Ness \& Xing, 2017). Therefore, transition to circular and sustainable construction processes are required to promote sustainable development.

The way cities are developed can mitigate these impacts by designing and constructing our buildings for low energy and resource consumption. The global trend towards urbanisation is projected to continue with the global urban population rising from $54 \%$ in 2018 to over $60 \%$ by 2025 . The growing pace of urbanisation leads to increasing demands for infrastructure and buildings, and growing consumption of products and services. This makes cities one of 
the most critical intervention points for reducing human impact on the environment, creating sustainable local economies and increasing the average quality of human life. Within cities the built environment has the potential to play a key role in reducing environmental impacts, as this is the place where the energy transition and circular transition come together. The construction industry accounts for about $50 \%$ of our total use of raw materials. Furthermore, the built environment is responsible for $40 \%$ of $\mathrm{CO}_{2}$ emissions and $36 \%$ of energy consumption. Addressing these impacts through circular and climate neutral development is thus crucial (Kubbinga et al., 2018).

If a comprehensive look on possible circular processes is taken (see Figure 4), it is hard to draw the frame of circular construction and real estate processes. It is obvious that they are central processes but other processes can not be separated from them because in that case the supply chain loop would not be closed as it is stated in fundamentals of circular economy concept. Therefore, authors acknowledge that circular construction processes are based on systems thinking as it is stated in significant part of studies related to circular economy (World Economic Forum, 2018).

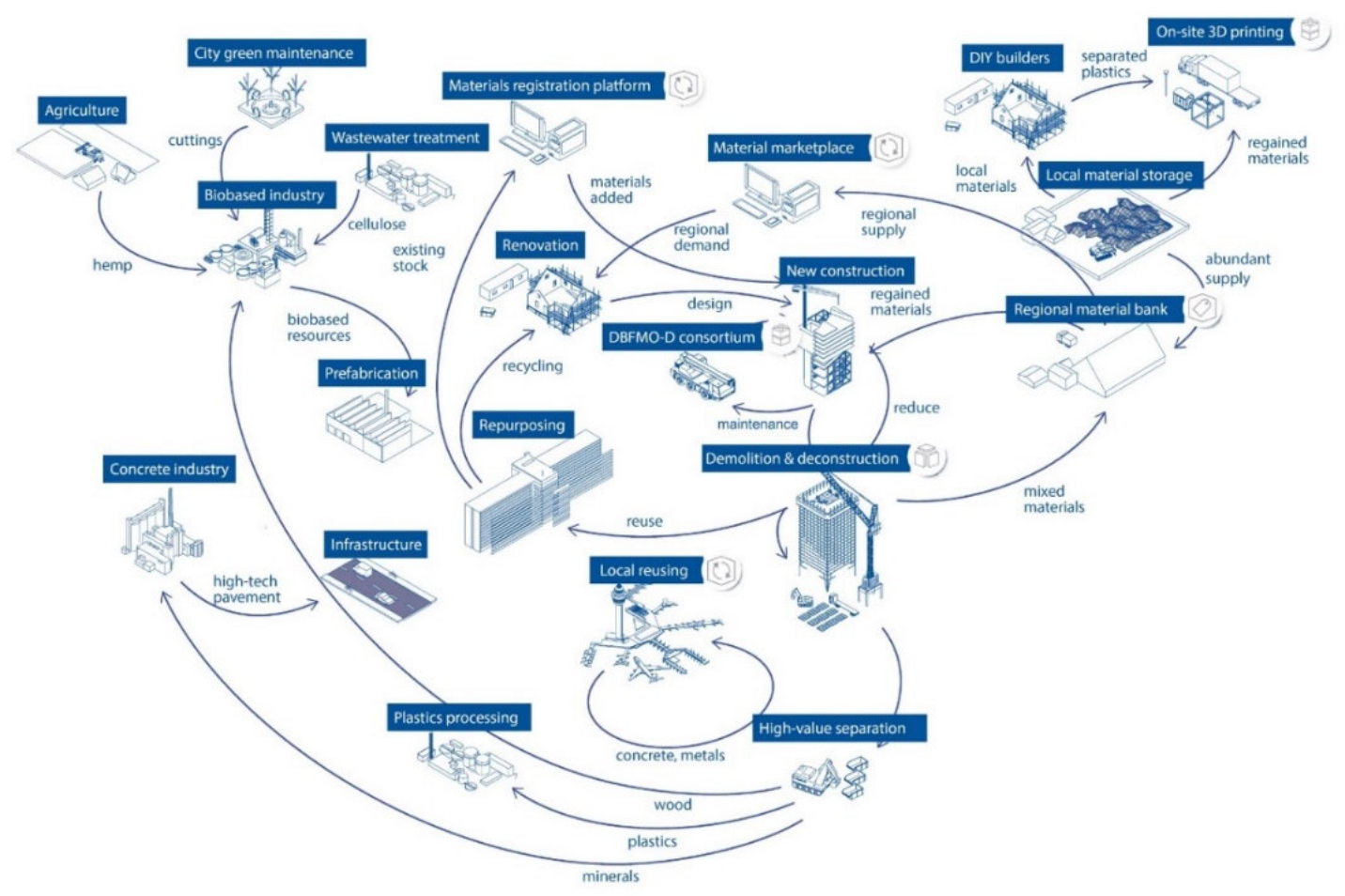

Figure 4. Process relation in circular economy (source: UK Green Building Council, 2017)

Developing timber buildings can be a good solution for sustainable and circular cities. Hossain and $\mathrm{Ng}$ indicate that in comparison to residential buildings constructed with concrete, about $25 \%$ lower carbon emission level can be achieved if residential buildings are made of wood (Hossain \& $\mathrm{Ng}, 2018$ ). Therefore, wood can be considered as a circular material, additionally being renewable and thus sustainable as well.

Circular economy concept is having an impact on the business models regarding the 'product as a service concept', in which companies guarantee a performance at a periodic fee and no longer deliver a product but a service. The manufacturer keeps control over this product while smart design facilitates effective reuse. In the construction industry this business model is particularly suitable for high-tech products such as lifts and climate control systems. The complexity of these products is giving the supplier a knowledge advantage. That can result in a supplier being in a position to provide efficient service maintenance (van Sante, 2017).

Ways of implementing a circular economy in cities are undergoing a period of active evolution. Urban circular economy contributes to the development of sustainable societies. There are many practitioners who are committed to solving environmental problems. Recommendations for integrating the circular economy into the life of cities are divided into four main areas: recognition and use of different interests and spheres of influence; implementation of system solutions; adaptation to the local culture; introduction of the internal education system.

\section{Stakeholders in circular construction}

Demolishers, wholesalers in construction sector, suppliers of building materials, real estate investors, project developers, architects and contractors are actors in supply chains that are linked to each other by different kind of relationships, which develop a social network. 
There are several ways to make built environment circular. Circular construction starts with circular designs. When designing, the architects already take into account necessary changes. Maximising life span is another method, which refers to using a building for a long period of time so that the materials remain in use which highly relies on good maintenance. Constructing demountable buildings would be a way to implement circular construction, because in that way building materials can be easily dismantled and reused. Designing buildings with fewer materials can be linked to one of the main fundamentals of economics: "doing more with less". In that case, there would be significant resource savings, less construction waste and $\mathrm{CO}_{2}$ emissions. Another method is linked to renewable energy resources. Using biobased construction materials such as wood can stimulate circular processes in the long run and promote sustainable development conception. When a building is no longer suitable for current purpose, it can be transformed. Therefore, transformation as a method gives building materials a second life and exclude construction waste. If materials can not be transformed, they can serve as resources for other building structures. From these kind of resources material banks can be created. However, if a building can not be transformed or dismantled into separate components, it can be demolished with low-grade reuse of materials. All of these circular construction methods are linked to such fundamental circular processes as reusing, reducing, repairing and recycling, and can be adapted to existing buildings and new real estate projects (van Sante, 2017).

Occasionally stakeholders can be pushed to answer a simple question regarding circular construction: why now? There are several drivers, which are in favour of development of circular construction. One of them is the tendency that large corporate companies are attaching increasing importance to sustainability. Companies want to show their awareness of global challenges and therefore they include circularity in their corporate social responsibility (CSR) policies. Small and medium sized enterprises are becoming aware of this trend as well and they are collaborating with corporate companies and possibly giving them an opportunity to advertise their sustainability achievements. High ambitions at local authorities can also positively contribute to successful development of circular construction. Additionally, there is an added value for long-term investors, because a building which is constructed according to a circular paradigm has a flexible purpose. For example, office buildings can be transformed to apartments or hotels and they contain more value than a one-purpose building (van Sante, 2017).

Different supply chain partners have different view on circular construction. Not everyone within this concept is a 'winner'. By dismantling buildings rather than demolishing them appears an opportunity to sell high-grade building materials. Therefore, demolishers can deliver extra added value and end up being winners as well as wholesalers in the construction sector. Their opportunities lie in the reuse of materials. They can buy used building materials and create a materials bank. The advantage of wholesalers is that they have a network of contractors to which they can sell materials. Supplier of high-tech materials by offering maintenance or a service model can offer an extra benefit to circular construction and profit from that. Real estate investors as mentioned before can own buildings with added value. As the demand among users rises, building that can be converted for a different purpose has increased value.

There are also neutral stakeholders, who can find arguments in favour of promoting circular construction or against it. Project developers can promote circular innovation throughout the entire construction chain and therefore meet the increasing demand for circular construction among real estate investors and users. The architect promotes sustainable building methods and materials and designs buildings that are easy to transform or dismantle, but the role of architect in the supply chain is not changed by circular construction as well as contractor's role. Different building methods and sustainable building materials have to be used and reused. However, it is possible that there will be more emphasis on maintenance and renovation instead of carrying out new real estate projects.

The clear loser identified is supplier of low-tech building materials. Due to less use of new building materials the demand for new low-tech building materials could fall. Providing maintenance or service contracts for low-tech building materials is less likely to occur than for high-tech building materials according to development of circular construction (van Sante, 2017).

In order to efficiently implement circular construction, it should be profitable for majority of stakeholders within the concept. If there is no additional value provided for project developers, architects and contractors, their lack of interest and motivation could be a great barrier transitioning to circular construction implementation in practice. The change requires additional effort and energy, and if there will not be any additional benefits, which are gained by changing their way of operating, then successful implementation of circular construction practices is unlikely to occur. Additionally, changes require leadership from society and organizational support through creative collaboration processes among all stakeholders.

\section{Challenges and barriers in circular construction}

Transition to circular economy and circular construction is challenging and faces several barriers, which can be divided into 4 categories: financial, social, institutional, technical (see Table 2). Table shows and approves that transition to circular economy requires systemic changes. From the technical point of view products are designed to be disposed and the information sharing is not a part of successful entrepreneurship practices. Additionally, the methods of how to measure circularity and development linked to transition to circular economy have not been developed yet. Institutional barriers that are linked to complicated or inelastic regulatory structures are hindering any potential change and they are 
limiting integrated action and leadership. In the view of authors, the greatest barriers are social ones which are highly linked to resistance to change. Any sort of change requires additional effort and energy. And if there is no motivation or direct benefits, then societal members tend to maintain their status quo with their comfort level. Additionally, lack of awareness linked to such global issues as climate change, overpopulation, resource depletion and possible consequences interferes and demotivates the change of individual values and activities linked to environmental protection.

Table 2. Barriers for implementing circular economy (source: World Economic Forum, 2018)

\begin{tabular}{|l|l|l|l|}
\hline \multicolumn{1}{|c|}{ Financial } & \multicolumn{1}{|c|}{ Social } & \multicolumn{1}{c|}{ Institutional } & \multicolumn{1}{c|}{ Technical } \\
\hline High Transition Costs & $\begin{array}{l}\text { Lack of awareness and sense } \\
\text { of urgency }\end{array}$ & $\begin{array}{l}\text { The linear mindset has deep } \\
\text { roots }\end{array}$ & $\begin{array}{l}\text { Products are designed to } \\
\text { dispose }\end{array}$ \\
\hline Upfront Investment & Resistance to change & $\begin{array}{l}\text { Complicated or inelastic } \\
\text { regulatory structures }\end{array}$ & $\begin{array}{l}\text { Lack of information } \\
\text { exchange }\end{array}$ \\
\hline $\begin{array}{l}\text { Economic viability of } \\
\text { recycling }\end{array}$ & $\begin{array}{l}\text { Limited integrated action and } \\
\text { leadership }\end{array}$ & $\begin{array}{l}\text { Lack of metrics to measure } \\
\text { circularity }\end{array}$ \\
\hline
\end{tabular}

Authors can make an assumption that only when the majority of society will feel the destructive impacts of global problems like climate change and water scarcity on their 'skin', they will feel more concerned about ecological aspects and their values will spread beyond financial aspects. Therefore, it seems that educating society and making people aware of what is happening all around the globe could be a good practice for today.

\section{Synergy in circular economy and circular construction}

Geipele et al. in 2018 define synergy as 'interaction of two or more system elements that produce a combined effect greater than the sum of their separate effects' (Geipele, Plotka, Wirzhbitskis, \& Zvirgzdins, 2018).

Research scope of this article can be reflected with Figure 5. In the centre there is a multi-purpose real estate object. It does not necessarily mean that a real estate object should be an office and living area at the same time but it should contain an opportunity to be repurposed. Circular real estate is a product of circular construction, which however creates basis of built environment in circular city. And as long as the majority of the global population live in an urban environment, cities can be considered as the leading force bringing the concept of circular economy to life. Additionally, benefits of implementing this concept contain synergistic effects, which can promote all dimensions of sustainable development. For example, circular real estate object (green building) can be cost-effective, environmentally friendly and human friendly covering 'people', 'profit', 'planet' dimensions.

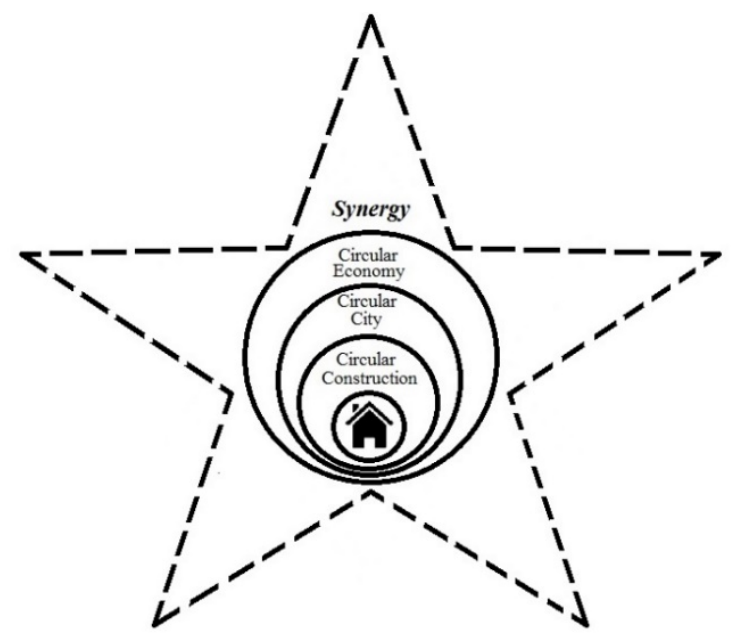

Figure 5. Circular construction and real estate within circular economy concept (developed by authors)

\section{Conclusions}

The concept of circular economy can contribute to such global issue solving as climate change, overpopulation, deforestation, urbanization, pollution. Resources within the concept of circular economy are cycled at continuous high value. Construction as an industry should be implementing designs and systems with improved long-term life cycle performance considering closed loop design principles. 
Information sharing and effective collaboration among all stakeholders considering significant aspects of materials, energy, water, biodiversity and ecosystems, human culture and society, health and wellbeing and value is a precondition of successful circular construction practice implementation.

The main incentive for high performance circular real estate advancement is a sustainable development paradigm that changes not only the physical structures of buildings, but also the activities of companies, organizations and individuals that live in the built environment.

In order to efficiently implement circular construction, it should be profitable for majority of stakeholders within the concept covering the economic dimension of sustainable development. Stakeholders have an important role in ensuring that the whole construction supply chain is developed with as many circular innovations as possible. Tenders for procurements of different kinds should be as flexible as possible to allow each participant of circular construction process to offer own innovative methods. That will leave space for development of innovation contributing to sustainable construction practices. Nowadays, there are significant gaps in the implementation of circular innovations in the built environment and real estate industry. The problem is that existing construction and real estate market parameters do not suit the needs of society and economy in $21^{\text {st }}$ century.

Effective coordination and collaboration between various stakeholders and sectors are required to integrate circular thinking in the majority of sustainable built environment and real estate industry covering the social, economic, environmental, technological, cultural and governmental dimensions. Current approaches to the built environment in context of circular economy remain fragmented and lacking a holistic approach by either focusing on the technical realization (Planning, Design and Construction), the way it can be regulated and financed (Policy Instruments), or how to promote participation of residents and communities (Social Empowerment).

Furthermore, the application of the principles of circular economy to the built environment and real estate industry can lead to a more effective management and use of water, waste, energy and material resources during all stages of the construction life cycle.

Transition to circular construction practices can be achieved with systemic changes. A good aspect to start with could be the education. There is not only a need for formal university education in field of sustainable construction, but also a need for technical school programs that have the ability to train and educate new industrial workforce for sustainable construction practices creating infrastructure for sustainable value creation. A new learning curriculum could promote a collaboration of researchers, policy-makers, practitioners and community representatives working in a multi-actor and interdisciplinary environment. Therefore, existing methods and tools should be transferred and adapted in order to promote development of a framework, which can facilitate understanding of the mutual interrelationships between circular economy and sustainability in built environment and real estate industry.

\section{References}

Barrie, K. (2017). Future Cities: driving the circular economy philosophy. Retrieved from https:/www.globalrealestateexperts.com/2017/10/future-cities-driving-circular-economic-philosophy/

Bouton, S., Hannon, E., Rogers, M., Swartz, S., Johnson, R., Gold, A., \& Staples, M. (2016). The circular economy: Moving from theory to practice (Special ed., 40). McKinsey center for business and environment. Retrieved from https://www.mckinsey.com/ /media/mckinsey/business\%20functions/sustainability\%20and\%20resource\%20productivity/o ur\%20insights/the $\% 20$ circular $\% 20$ economy $\% 20$ moving $\% 20$ from $\% 20$ theory $\% 20$ to $\% 20$ practice/the $\% 20$ circular $\% 20$ econom y $\% 20$ moving $\% 20$ from $\% 20$ theory $\% 20$ to $\% 20$ practice.ashx

De Wolf, C., Pomponi, F., \& Moncaster, A. (2017). Measuring embodied carbon dioxide equivalent of buildings: A review and critique of current industry practice. Energy and Buildings, 140, 68-80. https://doi.org/10.1016/j.enbuild.2017.01.075

Du Plessis, M. (2007). The role of knowledge management in innovation. Journal of Knowledge Management, 11(4), $20-29$. https://doi.org/10.1108/13673270710762684

Geipele, I., Plotka, K., Wirzhbitskis, Y., \& Zvirgzdins, J. (2018, December). The synergy in circular economy. In Third International Conference on Economic and Business Management (FEBM 2018). Advances in Economics, Business and Management Research (vol. 56, pp. 65-68). Atlantis Press. https://doi.org/10.2991/febm-18.2018.15

Geissdoerfer, M., Savaget, P., Bocken, N. M., \& Hultink, E. J. (2017). The circular economy - A new sustainability paradigm?. Journal of Cleaner Production, 143, 757-768. https://doi.org/10.1016/j.jclepro.2016.12.048

Hossain, M. U., \& Ng, S. T. (2018). Critical consideration of buildings' environmental impact assessment towards adoption of circular economy: An analytical review. Journal of Cleaner Production, 205, 763-780. https://doi.org/10.1016/j.jclepro.2018.09.120

Jaillon, L., \& Poon, C. S. (2014). Life cycle design and prefabrication in buildings: A review and case studies in Hong Kong. Automation in Construction, 39, 195-202. https://doi.org/10.1016/j.autcon.2013.09.006

Jones, P., \& Comfort, D. (2017). Towards the circular economy: A commentary on corporate approaches and challenges. Journal of Public Affairs, 17(4), e1680. https://doi.org/10.1002/pa.1680

Kibert, C. J. (2007). The next generation of sustainable construction. Journal Building Research \& Information, 35(6), 595-601. https://doi.org/10.1080/09613210701467040

Kubbinga, B., Bamberger, M., van Noort, E., van den Reek, D., Blok, M., Roemers, G., ..., \& Faes, K. (2018). A framework for circular buildings: indicators for possible inclusion in BREEAM. Circle Economy, DGBC, Metabolic, SGS Search, 52 p. 
Retrieved from https://www.circle-economy.com/wp-content/uploads/2018/10/A-Framework-For-Circular-BuildingsBREEAM-report-20181007-1.pdf

Lacy, P., \& Rutqvist, J. (2015). Waste to wealth: The circular economy advantage. London: Palgrave Macmillan. https://doi.org/10.1057/9781137530707

Ness, D. A., \& Xing, K. (2017). Toward a resource - efficient built environment: A literature review and conceptual model. Journal of Industrial Ecology, 21(3), 572-592. https://doi.org/10.1111/jiec.12586

Ofori, G. (1998). Sustainable construction: principles and a framework for attainment-comment. Construction Management \& Economics, 16(2), 141-145. https://doi.org/10.1080/014461998372448

Pomponi, F., \& Moncaster, A. (2017). Circular economy for the built environment: A research framework. Journal of Cleaner Production, 143, 710-718. https://doi.org/10.1016/j.jclepro.2016.12.055

Pukite, I., \& Geipele, I. (2017). Different approaches to building management and maintenance meaning explanation. Procedia Engineering, 172, 905-912. https://doi.org/10.1016/j.proeng.2017.02.099

Sanchez, B., \& Haas, C. (2018). Capital project planning for a circular economy. Construction Management and Economics, 36(6), 303-312. https://doi.org/10.1080/01446193.2018.1435895

Sassi, P. (2008). Defining closed-loop material cycle construction. Building Research \& Information, 36(5), 509-519. https://doi.org/10.1080/09613210801994208

Schultmann, F., \& Sunke, N. (2007). Energy-oriented deconstruction and recovery planning. Building Research \& Information, 35(6), 602-615. https://doi.org/10.1080/09613210701431210

Silvestre, J. D., de Brito, J., \& Pinheiro, M. D. (2014). Environmental impacts and benefits of the end-of-life of building materialscalculation rules, results and contribution to a "cradle to cradle" life cycle. Journal of Cleaner Production, 66, 37-45. https://doi.org/10.1016/j.jclepro.2013.10.028

Smith, S., \& Hung, P. (2015). A novel selective parallel disassembly planning method for green design. Journal of Engineering Design, 26(10-12), 283-301. https://doi.org/10.1080/09544828.2015.1045841

Tupenaite, L., Lill, I., Geipele, I., \& Naimaviciene, J. (2017). Ranking of sustainability indicators for assessment of the new housing development projects: Case of the Baltic States. Resources, 6(4), 55. https://doi.org/10.3390/resources6040055

UK Green Building Council. (2017). Practical how-to guide: Build circular economy thinking into your projects, 5. Retrieved from https://www.ukgbc.org/sites/default/files/How\%20to\%20build\%20circular\%20economy\%20thinking\%20into\%20your\%20 projects.pdf

van Sante, M. (2017). Circular construction. Most opportunities for demolishers and wholesalers. ING Bank N. V. 22 p. Retrieved from https://www.ing.nl/media/ING_EBZ_Circular-construction_Opportunities-for-demolishers-and-wholesalers_juni2017_tcm162-127568.pdf

World Economic Forum. (2018). Circular economy in cities: Evolving the model for a sustainable urban future. 29 p. Retrieved from http://www3.weforum.org/docs/White_paper_Circular_Economy_in_Cities_report_2018.pdf 